\title{
Effect of pulmonary artery catheter balloon inflation on pulmonary hemodynamics
}

\author{
Sravanthi Ennala ${ }^{1}$, Celia A. Melillo ${ }^{2}$, James E. Lane ${ }^{3}$, Adriano R. Tonelli ${ }^{4} \wedge$ \\ ${ }^{1}$ Department of Critical Care Medicine, Respiratory Institute, Cleveland Clinic, Cleveland, OH, USA; ${ }^{2}$ Inflammation and Immunity Department, \\ Cleveland Clinic, Cleveland, OH, USA; ${ }^{3}$ Nursing Institute, Cleveland Clinic, Cleveland, OH, USA; ${ }^{4}$ Department of Pulmonary, Allergy and Critical \\ Care Medicine. Respiratory Institute, Cleveland Clinic, Cleveland, OH, USA \\ Contributions: (I) Conception and design: AR Tonelli, CA Melillo; (II) Administrative support: CA Melillo; (III) Provision of study materials \\ or patients: AR Tonelli, CA Melillo, JE Lane; (IV) Collection and assembly of data: AR Tonelli, CA Melillo, JE Lane; (V) Data analysis and \\ interpretation: All authors; (VI) Manuscript writing: All authors; (VII) Final approval of manuscript: All authors. \\ Correspondence to: Adriano R. Tonelli, MD, MSc. Staff, Department of Pulmonary, Allergy and Critical Care Medicine. Respiratory Institute, \\ Cleveland Clinic, 9500 Euclid Avenue, Cleveland, OH 44195, USA. Email: tonella@ccf.org.
}

Background: Right heart catheterization (RHC), including a pulmonary artery wedge pressure (PAWP) determination, is necessary to categorize the hemodynamic type of pulmonary hypertension $(\mathrm{PH})$. The potential hemodynamic implications of a pulmonary artery catheter (PAC) balloon inflation in $\mathrm{PH}$ have not been formally tested.

Methods: We assessed the hemodynamic impact of the PAC balloon inflation during RHC by measuring systolic, diastolic, and mean pulmonary artery pressure (mPAP) in all patients, and cardiac output (CO) by thermodilution in a subgroup of patients. Hemodynamic measurements were obtained both with PAC balloon deflated and fully inflated $(1.5 \mathrm{~mL}$ of air), while the PAC was free floating in the pulmonary artery before wedging. We calculated total pulmonary resistance (TPR).

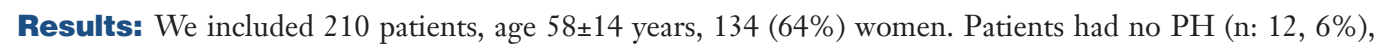
PH group 1 (n: 68, 33\%), 2 (n: 86, 41\%), 3 (n: 11, 5\%), 4 (n: 29, 14\%), and 5 (n: 3, 1\%). The mean \pm standard deviation (SD) at end-expiration mPAP (balloon-up minus down) (n: 209) was $-0.02 \pm 1.59 \mathrm{mmHg}$ (range, -5.0 to $4.0 \mathrm{mmHg}$; $\mathrm{P}=0.84$ ), while the TPR (n: 62) was $-0.27 \pm 1.2$ Wood units (WU) (range, -4.8 to 2.2 WU; $\mathrm{P}=0.08$ ); without significant variation based on the type of $\mathrm{PH}$ group or degree of pulmonary vascular resistance (PVR). Interestingly, the change in $\mathrm{mPAP}$ at end-expiration with PAC balloon inflation was higher in women (mean $\pm \mathrm{SD}: 0.31 \pm 1.43 \mathrm{mmHg}$ ) than men (mean $\pm \mathrm{SD}:-0.61 \pm 1.70 \mathrm{mmHg})(\mathrm{P}<0.001)$.

Conclusions: Balloon inflation of the PAC in the main pulmonary artery had no significant impact on the mPAP or TPR, even when only including patients with group $1 \mathrm{PH}$ or selecting a subgroup with a higher PVR.

Keywords: Pulmonary pressures; pulmonary hypertension (PH); mean pulmonary pressure; pulmonary artery wedge pressure (PAWP); pulmonary artery catheter (PAC)

Submitted Aug 19, 2021. Accepted for publication Dec 09, 2021.

doi: $10.21037 / \mathrm{cdt}-21-515$

View this article at: https://dx.doi.org/10.21037/cdt-21-515

^ ORCID: Sravanthi Ennala, 0000-0003-1632-0896; Adriano R. Tonelli, 0000-0002-2321-9545. 


\section{Introduction}

Pulmonary artery hemodynamics are essential for the diagnosis and hemodynamic classification of pulmonary hypertension $(\mathrm{PH})(1)$. $\mathrm{PH}$ is defined as a mean pulmonary artery pressure $(\mathrm{mPAP})>20 \mathrm{mmHg}$ and can be further characterized as precapillary [pulmonary artery wedge pressure (PAWP) $\leq 15 \mathrm{mmHg}$ with pulmonary vascular resistance (PVR) $\geq 3$ Wood units (WU)], post-capillary $\mathrm{PH}$ (PAWP $>15 \mathrm{mmHg}$ and $\mathrm{PVR}<3 \mathrm{WU}$ ) and combined pre- and post-capillary PH (PAWP $>15 \mathrm{mmHg}$ and PVR $\geq 3 \mathrm{WU}$ ) (1). A reliable PAWP determination is essential to this hemodynamic characterization (2); however, some physicians are concerned that the pulmonary artery catheter (PAC) balloon inflation in a pulmonary artery with already high mPAP may acutely affect the right ventricular (RV) afterload exposing patients to an increased risk of cardiovascular complications. The diameter of a fully inflated PAC balloon is $1.3 \mathrm{~cm}$ (area: $1.3 \mathrm{~cm}^{2}$ ), while the main pulmonary artery diameter in healthy individual and patient with $\mathrm{PH}$ is $2.5 \mathrm{~cm}$ (area: $4.9 \mathrm{~cm}^{2}$ ) and $3 \mathrm{~cm}$ (area: $\left.7.1 \mathrm{~cm}^{2}\right)$, respectively $(2,3)$. Therefore, a PAC balloon inflation represents reduction in effective vascular area of $27 \%$ in healthy and $18 \%$ in subjects with $\mathrm{PH}$, with unclear effects on pulmonary pressures. In fact, the potential hemodynamic implications of PAC balloon inflation in $\mathrm{PH}$ have not been formally tested. Therefore, we hypothesized that short-term balloon inflation has a minimal effect on pulmonary hemodynamics in most $\mathrm{PH}$ patients but may have a more relevant impact in those with severe $\mathrm{PH}$. We present the following article in accordance with the CONSORT for Harms reporting checklist (available at https://cdt.amegroups.com/article/view/10.21037/cdt-21$515 / \mathrm{rc})$.

\section{Methods}

The study was conducted in accordance with the Declaration of Helsinki (as revised in 2013). The institutional review board at Cleveland Clinic approved this study (number: 19-460). Informed consent was waived since the pressures presented are always recorded during right heart catheterization (RHC). RHC was performed under local anesthesia (lidocaine 1\%) to establish the diagnosis of $\mathrm{PH}$ or as hemodynamic evaluation during $\mathrm{PH}$ follow-up. The procedure was performed by a single operator (ART). In all patients, we advanced a 7.5-Fr PAC (Biosensor International, Jalan Tukang, Singapore) to the right or left main pulmonary artery. Patients who needed other PAC brands or sizes were excluded from the study. Catheter position was confirmed by waveform analysis and fluoroscopy imaging.

We recorded waveform tracings from three respiratory cycles for all hemodynamic determinations, and pressures were determined using calipers. We measured systolic, diastolic, and mPAP both at end-expiration and across the respiratory cycle. Cardiac output (CO) was measured by the thermodilution method (the distal thermistor is located before the PAC balloon, not affecting thermodilution measurements when the balloon is inflated) (4). Total pulmonary resistance (TPR) was calculated as mPAP/ $\mathrm{CO}$ hemodynamic determinations were obtained in the pulmonary artery both with the balloon deflated and fully inflated $(1.5 \mathrm{~mL}$ of air) just before advancing the PAC to a wedge position (Figure 1). Only TPR was compared between the two conditions, since only PAP but not PAWP (a value needed to calculated PVR) could be determined when the PAC balloon was inflated but free floating in the pulmonary artery. We also recorded the type of $\mathrm{PH}(1)$, clinical, laboratory, echocardiographic, radiographic, and functional data closest to the RHC.

\section{Statistical analysis}

Continuous data are presented as mean \pm standard deviation (SD) and categorical data are summarized as discrete values and percentages [n (\%)]. Paired Student's $t$-test was used to compare continuous variables before and during PAC balloon inflation. ANOVA and Chi-square were used to compare continuous and categorical variables, respectively, across the $\mathrm{PH}$ groups 1, 2 and 4. All $\mathrm{P}$ values are two-tailed and a value of $<0.05$ was considered significant. The statistical analyses were performed using the statistical package IBM SPSS, version 22 (IBM; Armonk, New York, NY, USA).

\section{Results}

We included 210 unique patients between December 2019 and December 2020, age 58 \pm 14 years, $134(64 \%)$ women. Patients had no PH (n: 12, 6\%), PH group 1 (n: 68, 33\%), 2 (n: 86, 41\%), 3 (n: 11, 5\%), 4 (n: 29, 14\%), and 5 (n: 3, 1\%). Group 1 PH included idiopathic (n: 32, 47\%) and heritable PAH (n: 7, 10\%), as well as PAH associated with liver disease (n: 4, 6\%), connective tissue disease (n: 22, 32\%) and drug/toxin (n: 3, 4\%). In the overall cohort, we noted minimal variation in the mPAP either at end-expiration or 

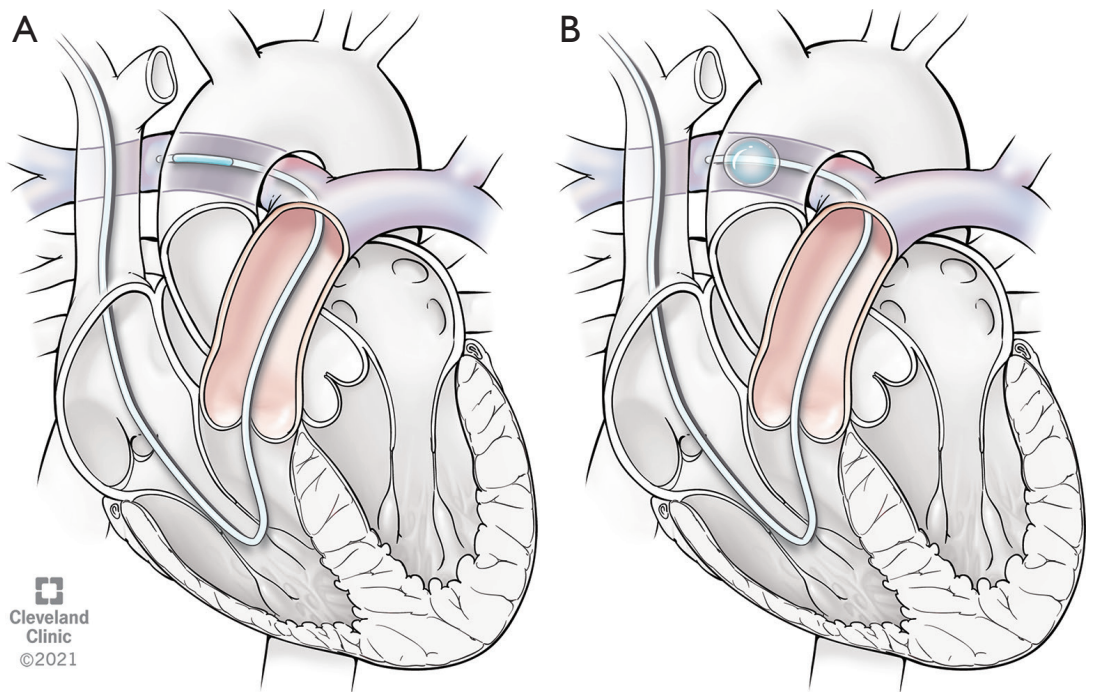

Figure 1 Pulmonary artery catheterization. (A) The PAC is located in the right pulmonary artery with balloon deflated. (B) The PAC is in the same location but with balloon inflated. PAC, pulmonary artery catheter.

Table 1 Hemodynamic determination with PAC balloon down and up

\begin{tabular}{lcccc}
\hline Hemodynamic determinations & $\mathrm{N}$ & $\begin{array}{c}\text { Balloon-down } \\
\text { determinations, mean } \pm \text { SD }\end{array}$ & $\begin{array}{c}\text { Balloon-up determinations, } \\
\text { mean } \pm \text { SD }\end{array}$ & $\begin{array}{c}\text { Pressure difference (up P (paired } \\
\text { minus down), mean } \pm \text { SD }\end{array}$ \\
\hline -test)
\end{tabular}

* , determinations averaged across the respiratory cycle; ${ }^{\S}, \mathrm{CO}$ and TPR are shown for those with determinations both with balloon up and down. PAC, pulmonary artery catheter; SD, standard deviation; PAP, pulmonary artery pressure; CO, cardiac output; TPR, total pulmonary resistance; WU, Wood units.

averaged across the respiratory cycle (Table 1). The mean $\pm \mathrm{SD}$ at end-expiration mPAP (balloon-up minus down) (n: 209) was $-0.02 \pm 1.59 \mathrm{mmHg}$ (range, -5.0 to $4.0 \mathrm{mmHg}$; $\mathrm{P}=0.84$ ), while the TPR (n: 62) was $-0.27 \pm 1.2 \mathrm{WU}$ (range, -4.8 to $2.2 \mathrm{WU}$; $\mathrm{P}=0.08$ ) (Table 1). For $\mathrm{PH}$ group 1 patients, the mean \pm SD difference in $\mathrm{mPAP}$ at end-expiration and TPR were $0.24 \pm 1.79 \mathrm{mmHg}(\mathrm{P}=0.27)$ and $-0.38 \pm 1.41 \mathrm{WU}$ $(\mathrm{P}=0.14)$, respectively. Interestingly, with balloon inflation, the mPAP averaged across the respiratory cycle was $0.54 \pm 1.76 \mathrm{mmHg}(\mathrm{P}<0.001)$ and $0.93 \pm 1.89 \mathrm{mmHg}$ $(\mathrm{P}<0.001)$ higher for the entire cohort and for the group of patients with $\mathrm{PAH}$, respectively.

The changes in mPAP at end-expiration or TPR did not vary significantly among $\mathrm{PH}$ groups (Table 2). With balloon inflation the mPAP at end-expiration increased in women (mean \pm SD: $0.31 \pm 1.43 \mathrm{mmHg}$ ), while it decreased in men $($ mean $\pm \mathrm{SD}:-0.61 \pm 1.70 \mathrm{mmHg})(\mathrm{P}<0.001 ; t$-test $)$. Besides gender, no other factors shown in Table 2 were associated with the difference (balloon up minus down) in mPAP at end-expiration or TPR. In addition, when patients with PAH were divided in subgroups based on the median PVR, i.e., PVR $<6$ and PVR $\geq 6 \mathrm{WU}$, we noted no significant 
Table 2 Clinical and hemodynamic determinations per PH group

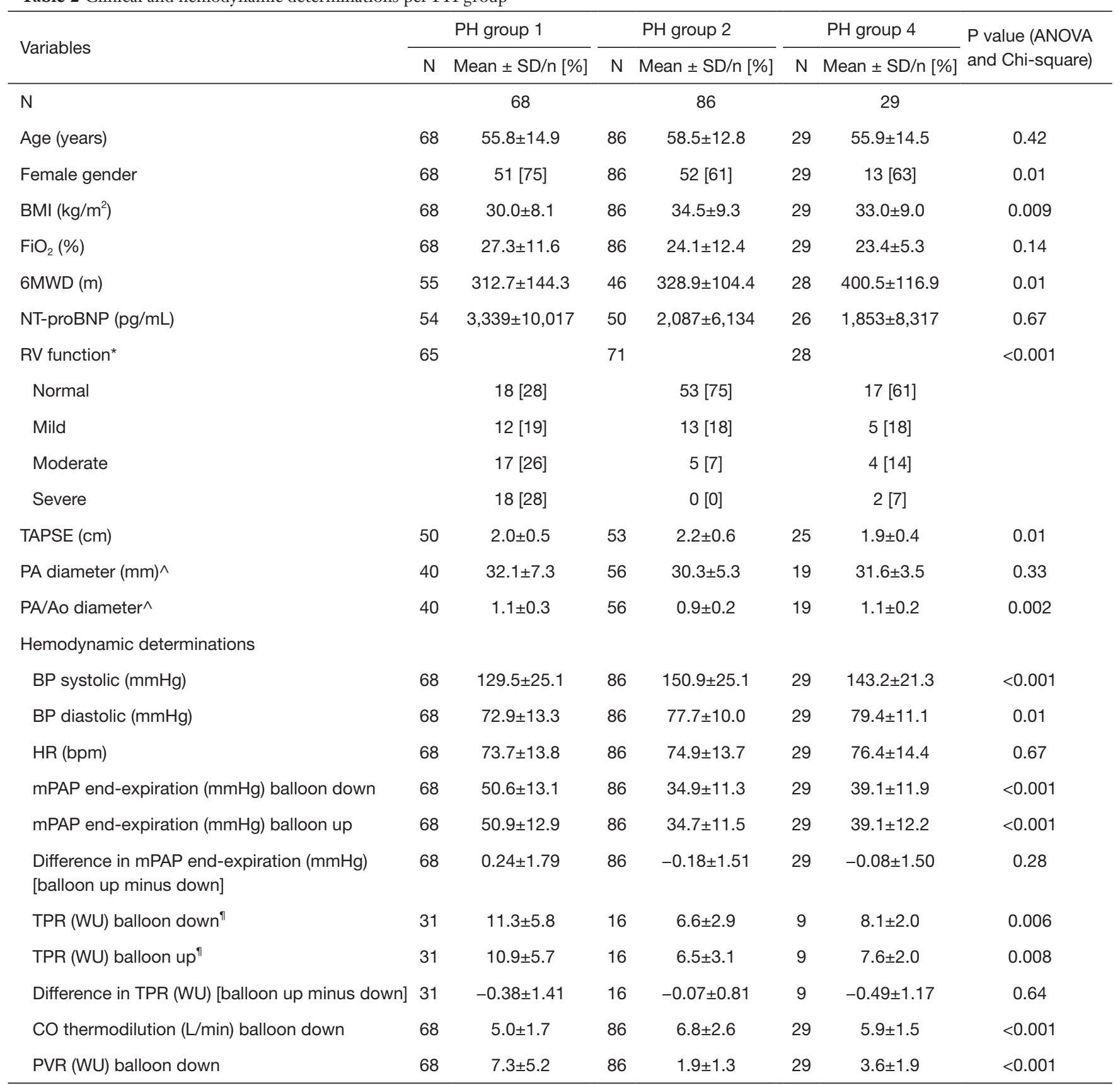

*, by echocardiogram using TAPSE and overall subjective contractility assessment; $\wedge$, by computed tomography of the chest; ", TPR only reported for subjects who also had TPR measured with balloon up. Clinical, echocardiographic, and functional determinations were obtained from evaluations performed within a month of the RHC. PH, pulmonary hypertension; SD, standard deviation; BMI, body mass index; $\mathrm{FiO}_{2}$, fraction of inspired oxygen; 6MWD, 6-minute walk distance; NT-proBNP, N terminal-pro-brain natriuretic peptide; RV, right ventricular; TAPSE, tricuspid annular plane systolic excursion; PA, pulmonary artery; Ao, aorta; BP, blood pressure; HR, heart rate; mPAP, mean pulmonary artery pressure; TPR, total pulmonary resistance; WU, Wood units; CO, cardiac output; PVR, pulmonary vascular resistance; $\mathrm{RHC}$, right heart catheterization. 
difference in the change between balloon up minus down,

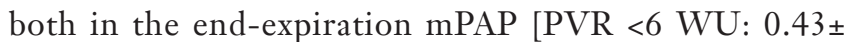
$1.9 \mathrm{mmHg}(\mathrm{n}=36) v s . \mathrm{PVR} \geq 6 \mathrm{WU}: 0.03 \pm 1.7 \mathrm{mmHg}(\mathrm{n}=32)$; $\mathrm{P}=0.37$ ], and TPR [PVR $<6 \mathrm{WU}:-0.06 \pm 1.1 \mathrm{WU}(\mathrm{n}=18) v s$. PVR $\geq 6$ WU: $-0.83 \pm 1.7$ WU $(n=13) ; \mathrm{P}=0.14]$.

\section{Discussion}

In this cohort of predominantly $\mathrm{PH}$ patients, we noted that total balloon inflation of the PAC in the main pulmonary artery had no significant impact on the mPAP or TPR, even when only including patients with group $1 \mathrm{PH}$ or selecting a subgroup with a higher PVR. Besides higher increases in mPAP with PAC balloon inflation in women, no other study variable (including those that track with $\mathrm{PH}$ severity) predicted a higher increase in MPAP or TPR with balloon inflation. Limitations of our study include (I) CO and therefore TPR with balloon up was measured in about a third of patients since this was a variable not initially included in our study protocol, and (II) we cannot exclude temporal variation in the hemodynamic measurements (5). The data presented supports that short-term PAC balloon inflation for PAWP determination has minimal hemodynamic implications in patients with $\mathrm{PH}$ and appears safe, even in patients with PAH.

\section{Acknowledgments}

Funding: None.

\section{Footnote}

Reporting Checklist: The authors have completed the CONSORT for Harms reporting checklist. Available at https://cdt.amegroups.com/article/view/10.21037/cdt-21$515 / \mathrm{rc}$

Data Sharing Statement: Available at https://cdt.amegroups. com/article/view/10.21037/cdt-21-515/dss

Peer Review File: Available at https://cdt.amegroups.com/ article/view/10.21037/cdt-21-515/prf

Conflicts of Interest: All authors have completed the ICMJE uniform disclosure form (available at https://cdt.amegroups. com/article/view/10.21037/cdt-21-515/coif). ART serves as an unpaid editorial board member of Cardiovascular Diagnosis and Therapy from September 2021 to August 2023.
The other authors have no conflicts of interest to declare.

Ethical Statement: The authors are accountable for all aspects of the work in ensuring that questions related to the accuracy or integrity of any part of the work are appropriately investigated and resolved. The study was conducted in accordance with the Declaration of Helsinki (as revised in 2013). The institutional review board at Cleveland Clinic approved this study (number: 19-460). Informed consent was waived since the pressures presented are always recorded during right heart catheterization.

Open Access Statement: This is an Open Access article distributed in accordance with the Creative Commons Attribution-NonCommercial-NoDerivs 4.0 International License (CC BY-NC-ND 4.0), which permits the noncommercial replication and distribution of the article with the strict proviso that no changes or edits are made and the original work is properly cited (including links to both the formal publication through the relevant DOI and the license). See: https://creativecommons.org/licenses/by-nc-nd/4.0/.

\section{References}

1. Simonneau G, Montani D, Celermajer DS, et al. Haemodynamic definitions and updated clinical classification of pulmonary hypertension. Eur Respir J 2019;53:1801913.

2. Tonelli AR, Mubarak KK, Li N, et al. Effect of balloon inflation volume on pulmonary artery occlusion pressure in patients with and without pulmonary hypertension. Chest 2011;139:115-21.

3. Raymond TE, Khabbaza JE, Yadav R, et al. Significance of main pulmonary artery dilation on imaging studies. Ann Am Thorac Soc 2014;11:1623-32.

4. Khirfan G, Ahmed MK, Almaaitah S, et al. Comparison of Different Methods to Estimate Cardiac Index in Pulmonary Arterial Hypertension. Circulation 2019;140:705-7.

5. Melillo CA, Lane JE, Aulak KS, et al. Repeatability of Pulmonary Pressure Measurements in Patients with Pulmonary Hypertension. Ann Am Thorac Soc 2020;17:1028-30.

Cite this article as: Ennala S, Melillo CA, Lane JE, Tonelli AR. Effect of pulmonary artery catheter balloon inflation on pulmonary hemodynamics. Cardiovasc Diagn Ther 2022;12(1):37-41. doi: 10.21037/cdt-21-515 